M. Meaney $\cdot$ S. Haughey $\cdot$ G. P. Brennan

I. Fairweather

\title{
A scanning electron microscope study on the route of entry of clorsulon into the liver fluke, Fasciola hepatica
}

Published online: 21 April 2005

(C) Springer-Verlag 2005

\section{Parasitol Res (2005) 95:117-128}

Figures 1-29 appeared too dark in the printed version of the article. The correct figures are shown here.
The online version of the original article can be found at http:// dx.doi.org/10.1007/s00436-004-1259-5

M. Meaney $\cdot$ S. Haughey $\cdot$ G. P. Brennan · I. Fairweather $(\square)$ Parasite Proteomics and Therapeutics Research Group,

School of Biology and Biochemistry,

Medical Biology Centre,

The Queen's University of Belfast,

97 Lisburn Road, BT9 7BL

Belfast, Northern Ireland

E-mail: i.fairweather@qub.ac.uk

Tel.: + 44-28-90972298

Fax: $+44-28-90335877$
Figs. 1-6 Scanning electron micrographs (SEMs) of the tegumental surface of control (Figs. 1,2) and clorsulon-treated (Figs. 3-6) Fasciola hepatica which had been incubated in vitro for $24 \mathrm{~h}$ (non-ligatured flukes)

Fig. 1 The ventral surface of a control fluke showing the oral sucker $(O S)$ and ventral sucker $(V S)$ on the apical cone of the fluke. The cirrus $(C)$ is also visible extending from the gonopore. Bar $2 \mathrm{~mm}$

Fig. 2 Spines $(S)$ from the anterior midbody region of the dorsal surface of a control fluke. Serrated tips can be seen on a number of the spines. Bar $50 \mu \mathrm{m}$

Fig. 3 Ventral surface of the apical cone showing the oral sucker $(O S)$, ventral sucker $(V S)$ and the gonopore $(G)$. Spines $(S)$ can be seen covering the surface of the tegument. Bar $400 \mu \mathrm{m}$

Fig. 4 Dorsal surface of the apical cone showing sunken spines $(S S)$ and severe swelling of the tegument both covering (white arrows) and between (black arrows) the spines. Bar $200 \mu \mathrm{m}$

Fig. 5 Spines from the lateral margin of the ventral, anterior midbody region. Severe swelling of the tegument can be seen between the spines (arrows). The tegument covering the spines $(S)$ is also severely swollen. Bar $60 \mu \mathrm{m}$

Fig. 6 The lateral margin on the dorsal surface of the posterior midbody region. Spines $(S)$ can be seen protruding from the swollen tegument (white arrows) that surrounds them, and the tegument covering the spines themselves is also swollen (black arrows). Bar $50 \mu \mathrm{m}$ 

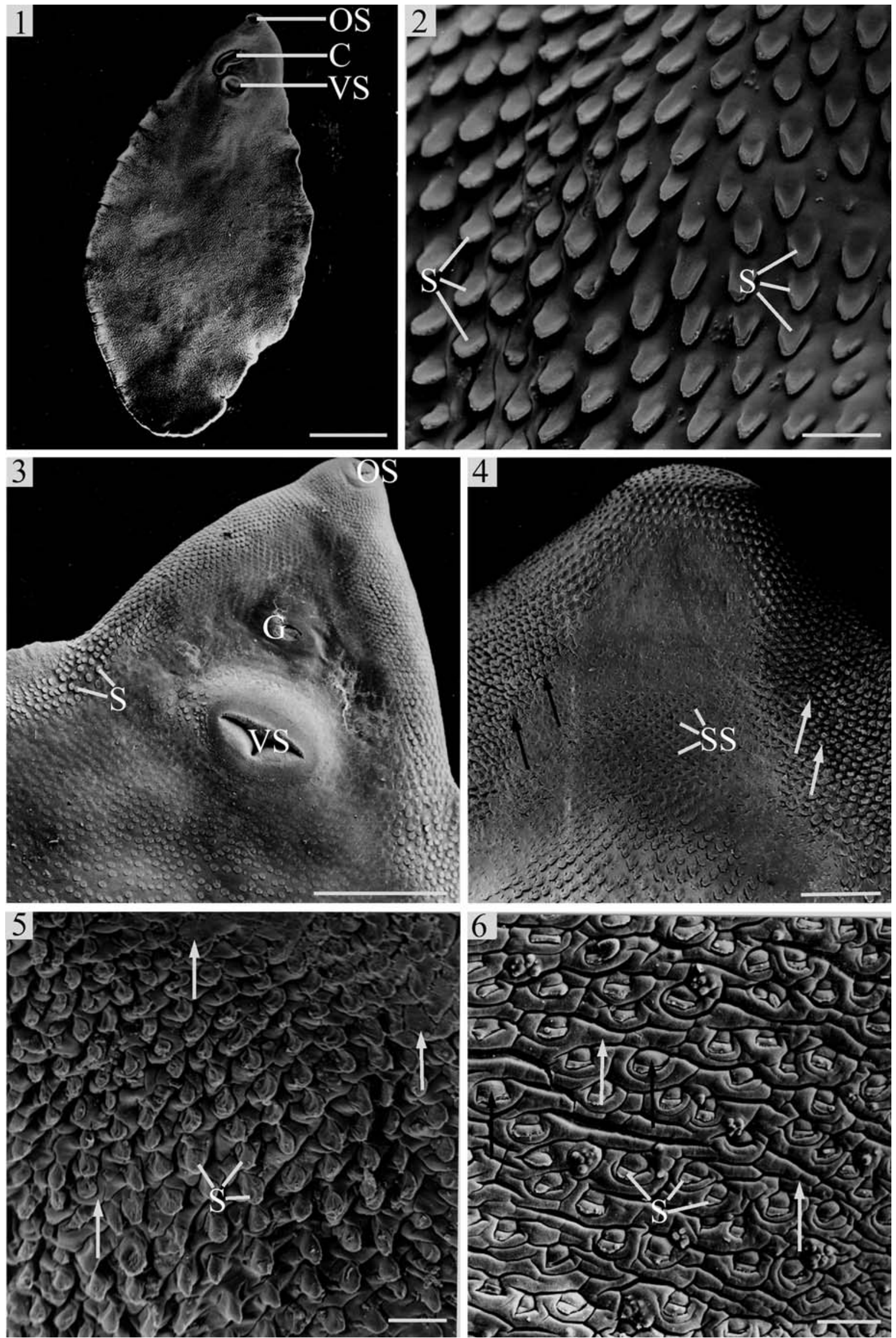

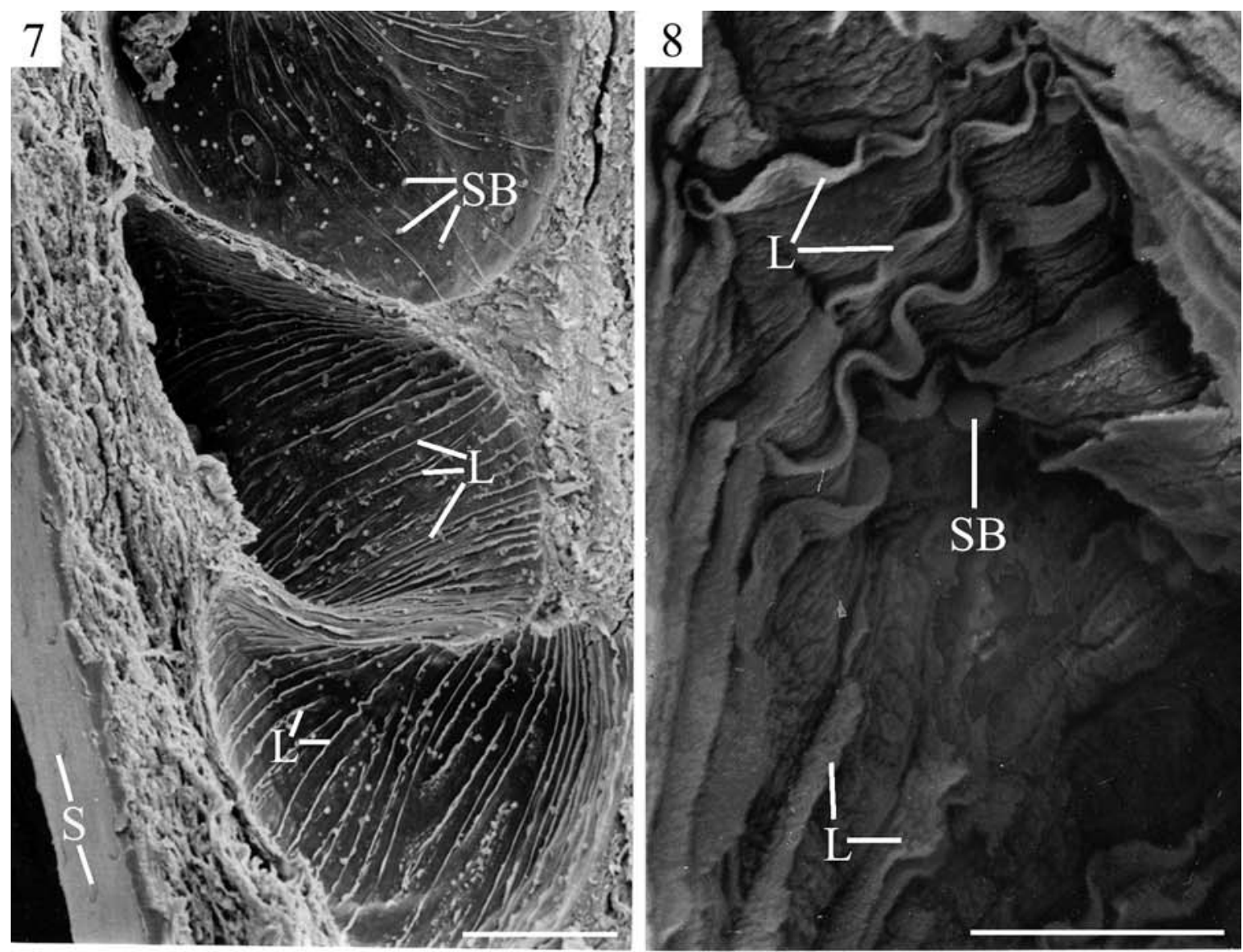

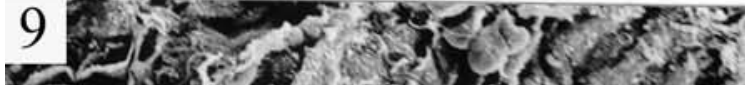
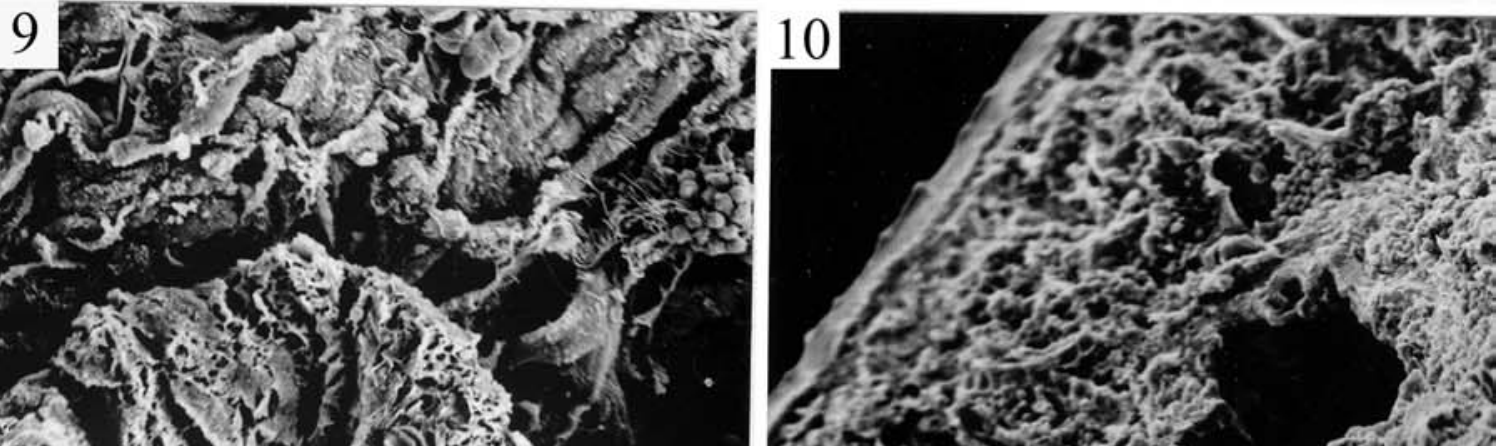

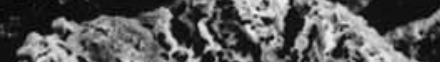

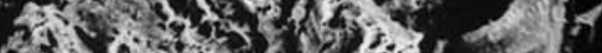

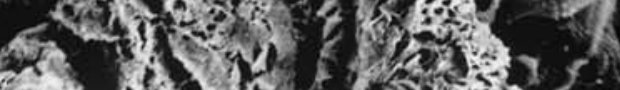
Fin of (2) vitur.

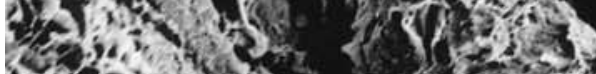

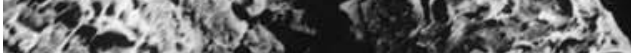
- $h, n$

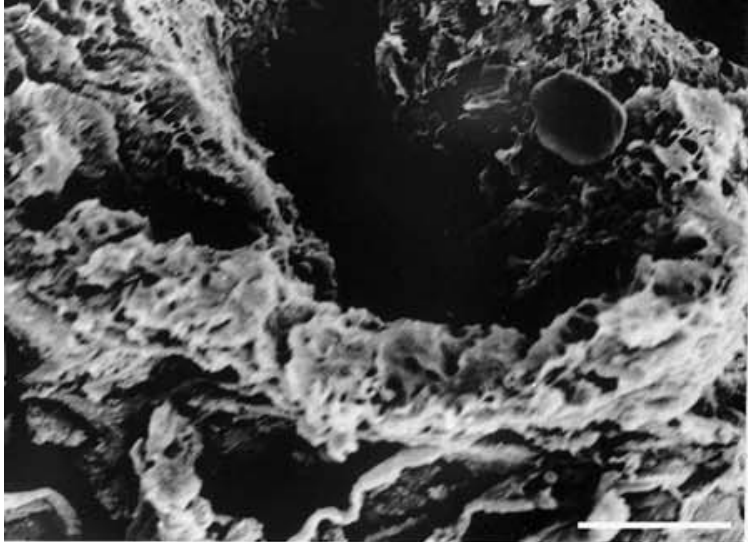
(1)

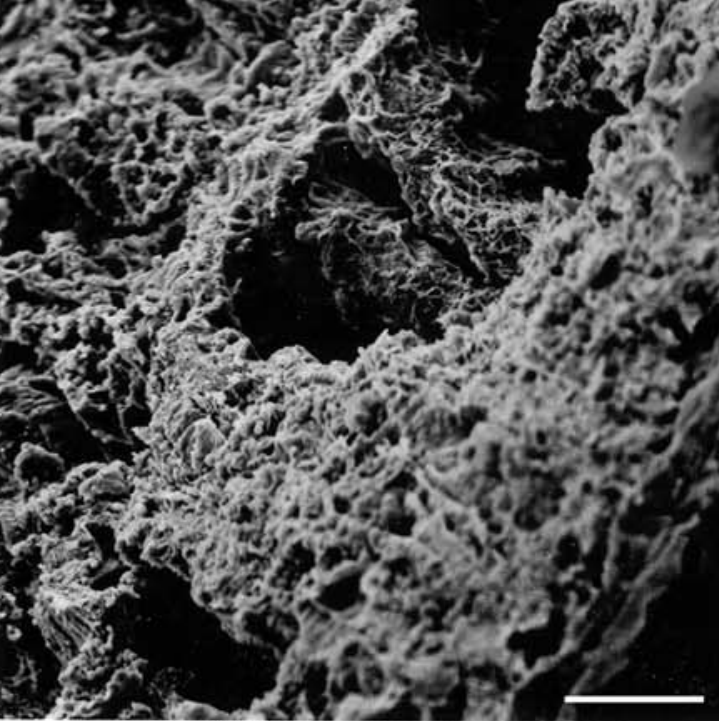


Figs. 7-10 Scanning electron micrographs (SEMs) of the gut of control (Figs. 7, 8) and clorsulon-treated (Figs. 9, 10) Fasciola hepatica which had been incubated in vitro for $24 \mathrm{~h}$ (non-ligatured flukes)

Fig. 7 The gut lumen of a control fluke in which the lamellae $(L)$ can be seen. Spherical bodies $(S B)$ are present on the surface of the lamellae and spines $(S)$ can also be seen on the tegumental surface of the fluke. Bar $200 \mu \mathrm{m}$

Fig. 8 High-power SEM of the gut of a control fluke. Large rippled lamellae $(L)$ can be seen extending into the lumen and a spherical body $(S B)$ is also present on the surface of a lamella. Bar $10 \mu \mathrm{m}$ Fig. 9 A region of gut in which the lamellae are so disrupted as to be unrecognisable. Bar $75 \mu \mathrm{m}$

Fig. 10 A severely disrupted region of gut in which the lamellae are disrupted and the tissue appears necrotic. Bar $100 \mu \mathrm{m}$

Figs. 11-15 Scanning electron micrographs (SEMs) of control (Figs. 11, 12) and clorsulon-treated (Figs. 13-15) Fasciola hepatica whose apical cone had been ligatured prior to incubation in vitro for $24 \mathrm{~h}$

Fig. 11 Control SEM showing the ligature $(L)$ below the oral sucker $(O S)$. The gonopore $(G)$ and the ventral sucker $(V S)$ can also be seen on the apical cone. Bar $250 \mu \mathrm{m}$

Fig. 12 Spines $(S)$ covering the tegument on the dorsal surface in the posterior midbody region of a control fluke. The spines and the tegument appear normal. Bar $150 \mu \mathrm{m}$

Fig. 13 Apical cone of a ligatured and treated fluke. Sloughing (arrows) of the apical plasma membrane of the tegument can be seen posterior to the oral sucker $(O S)$. The gonopore $(G)$ and the ventral sucker $(V S)$ can be seen anterior to the ligature $(L)$. Bar $200 \mu \mathrm{m}$

Fig. 14 Tegument and spines $(S)$ from the dorsal surface in the posterior midbody region. The surface appears normal. Bar $50 \mu \mathrm{m}$ Fig. 15 Swelling of the tegument (arrows) surrounding the spines in the tail region on the dorsal surface. Normal spines $(S)$ can be seen anterior to the tail in the posterior midbody region. Bar $200 \mu \mathrm{m}$ 

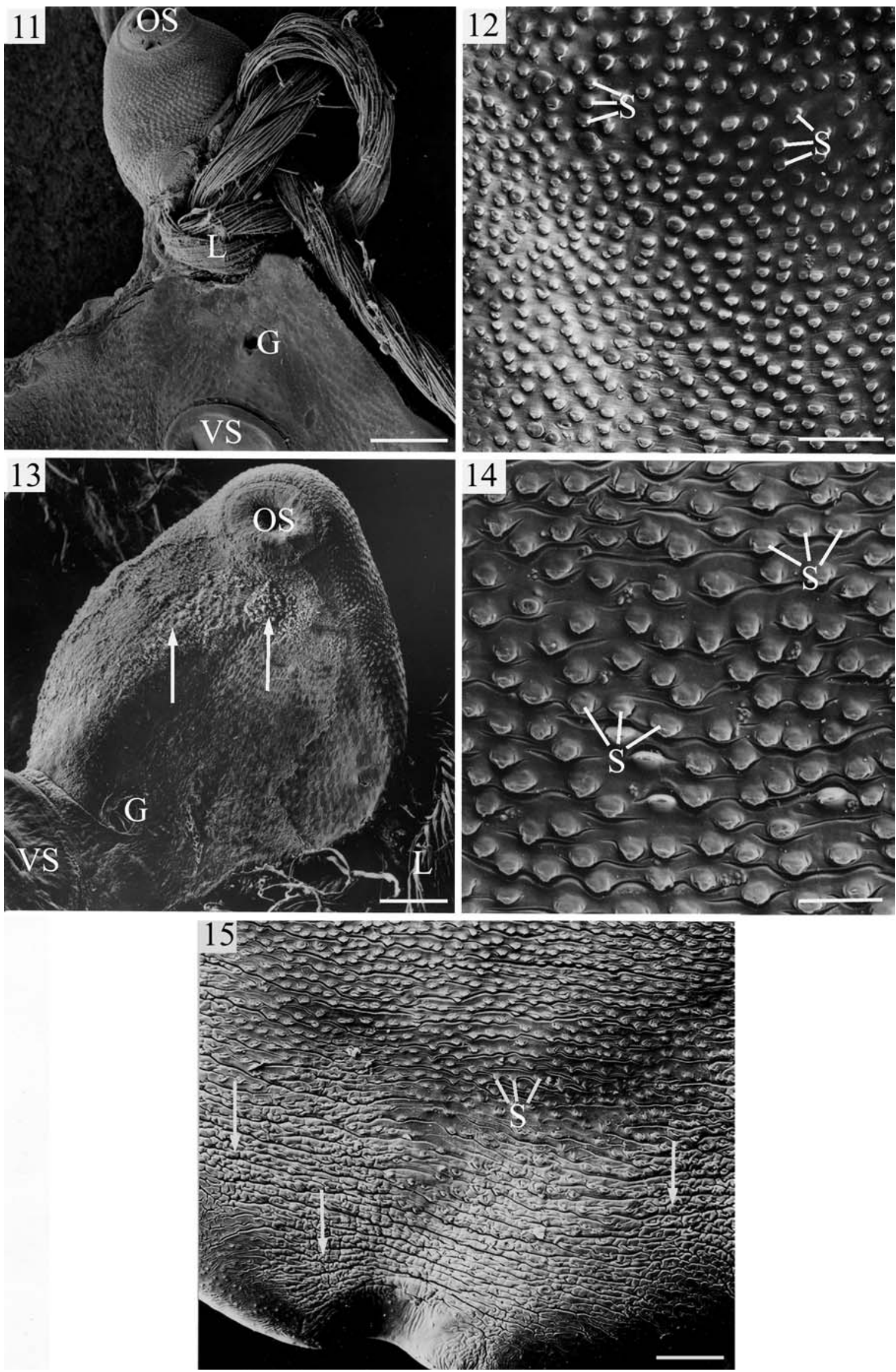

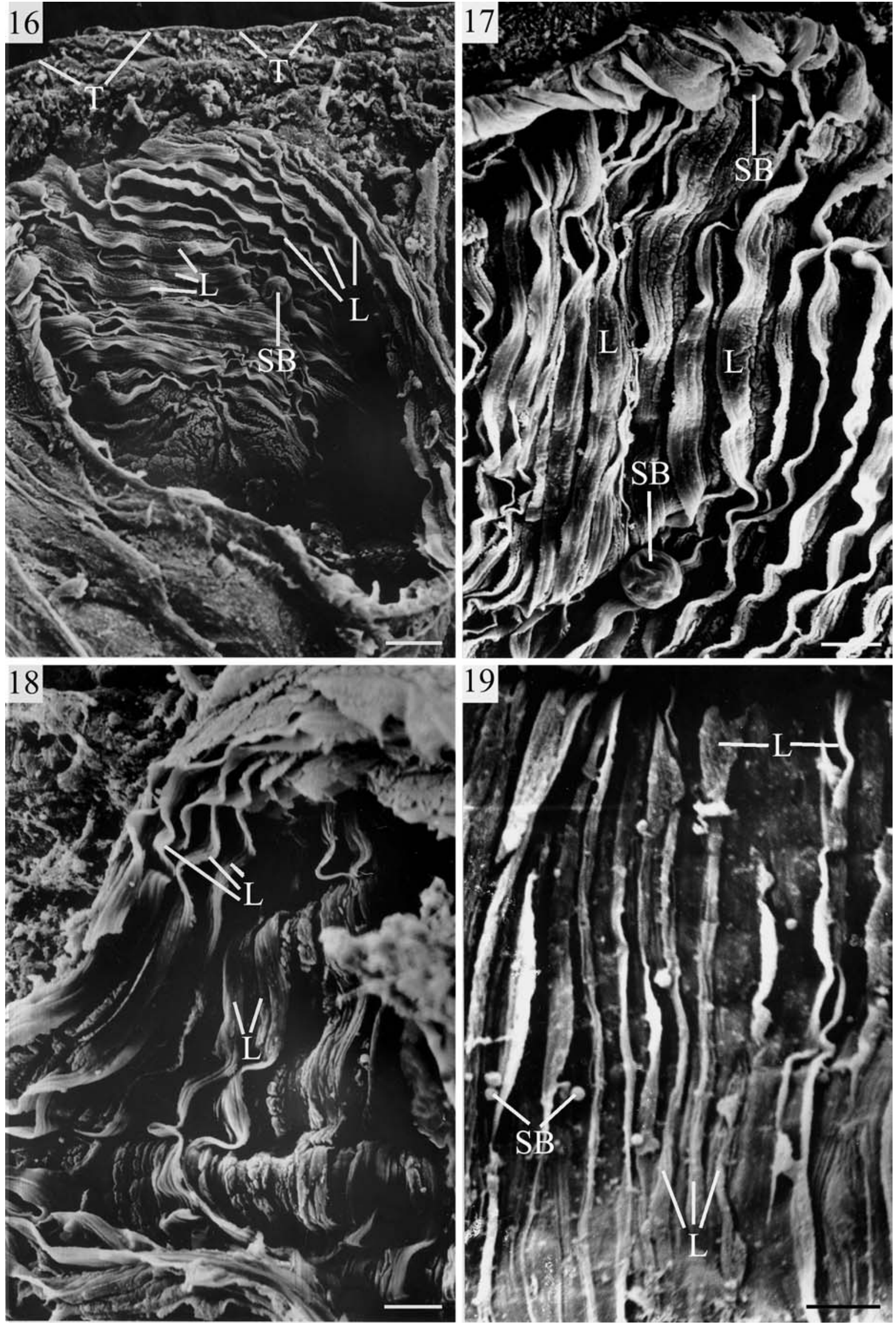
Figs. 16-19 Scanning electron micrographs (SEMs) of the gut of control (Figs. 16, 17) and clorsulon-treated (Figs. 18, 19) Fasciola hepatica whose apical cone had been ligatured prior to incubation in vitro for $24 \mathrm{~h}$

Fig. 16 Rippled sheets of lamellae $(L)$ inside the gut lumen of a control fluke. A large spherical body $(S B)$ is present on the surface of a lamella. The tegument $(T)$ can be seen above this section of gut. Bar $150 \mu \mathrm{m}$

Fig. 17 High-power SEM showing rippled sheets of lamellae $(L)$ and spherical bodies $(S B)$ in the gut of a control fluke. Bar $75 \mu \mathrm{m}$ Fig. 18 Gut from a treated fluke. Normal rippled lamellae $(L)$ can be seen extending into the lumen. Bar $75 \mu \mathrm{m}$

Fig. 19 High-power SEM from a treated fluke showing normal lamellae $(L)$ and spherical bodies $(S B)$ attached to them. Bar $100 \mu \mathrm{m}$
Figs. 20-25 Scanning electron micrographs (SEMs) of red blood cell-fed control (Figs. 20, 21) and clorsulon-bound red blood cellfed (Figs. 22-25) Fasciola hepatica which had been incubated in vitro for $24 \mathrm{~h}$

Fig. 20 Apical cone and ventral surface of a control fluke showing the oral sucker $(O S)$, cirrus $(C)$ protruding from the gonopore and the ventral sucker $(V S)$. Swelling of the tegument between the spines (arrows) can be seen between the oral sucker and cirrus. Bar $250 \mu \mathrm{m}$

Fig. 21 The anterior midbody region, towards the lateral margin on the dorsal surface of a control fluke. Slight swelling of the tegument (arrows) between and surrounding the spines $(S)$ is evident. Bar $75 \mu \mathrm{m}$

Fig. 22 Apical cone and dorsal surface showing disruption in the form of tegument sloughing at the tips of the spines (black arrows) and small blebs (white arrows) on the tegumental surface between the spines. Bar $75 \mu \mathrm{m}$

Fig. 23 Ventral surface, towards the lateral margin of the anterior midbody region, showing severe swelling of the tegument (white arrows) between the spines $(S)$ and also swelling of the tegument (black arrows) covering the backs of the spines. Bar $50 \mu \mathrm{m}$

Fig. 24 Ventral surface in the anterior midbody region showing blebs $(B)$ covering the surface of the tegument between the spines $(S)$. Most of the blebs have burst $(B B)$. Bar $20 \mu \mathrm{m}$

Fig. 25 Dorsal surface, in the posterior midbody region, showing microvillus-like projections $(M V)$ on both the tegument between and covering the spines $(S)$. Bar $20 \mu \mathrm{m}$ 

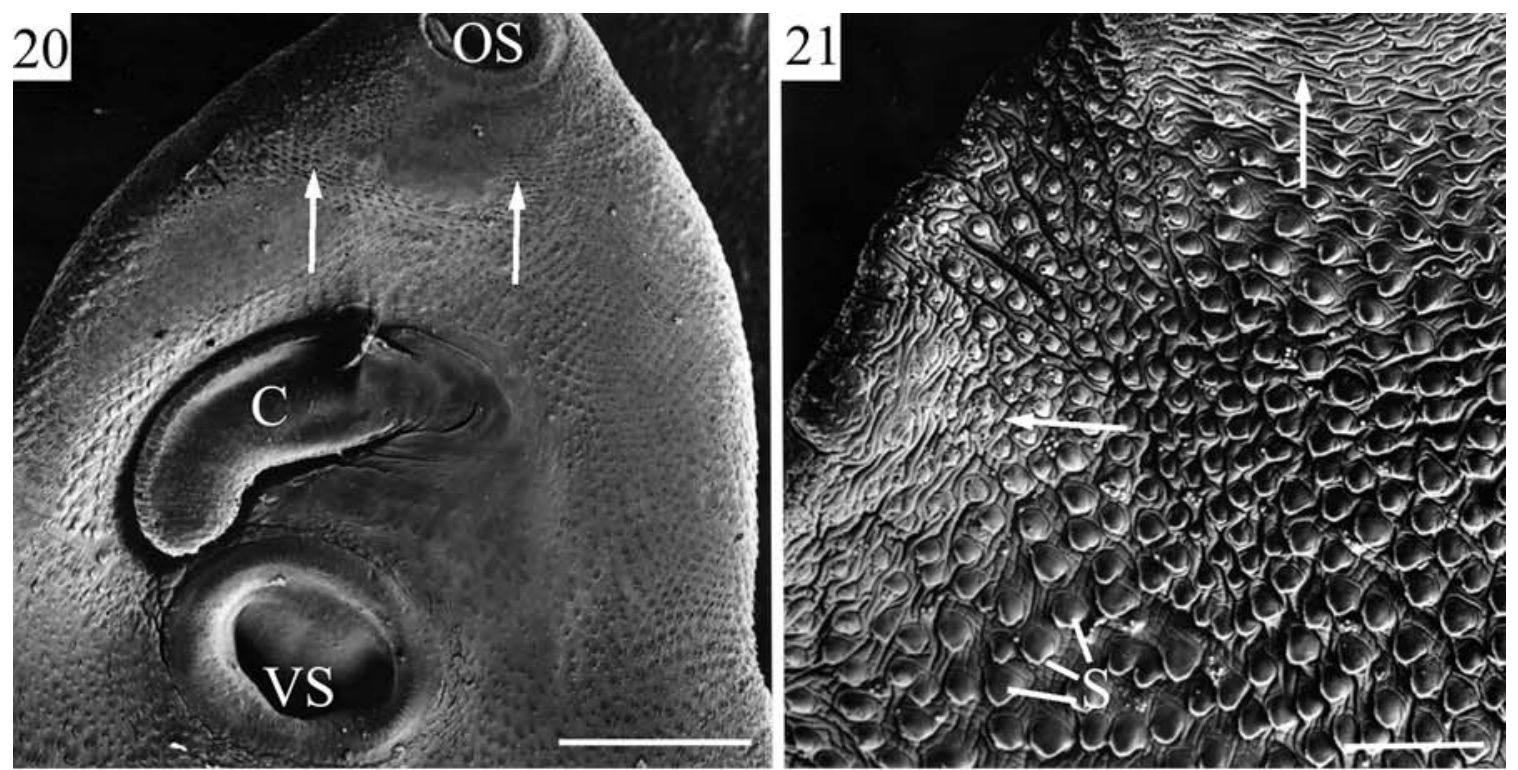

22
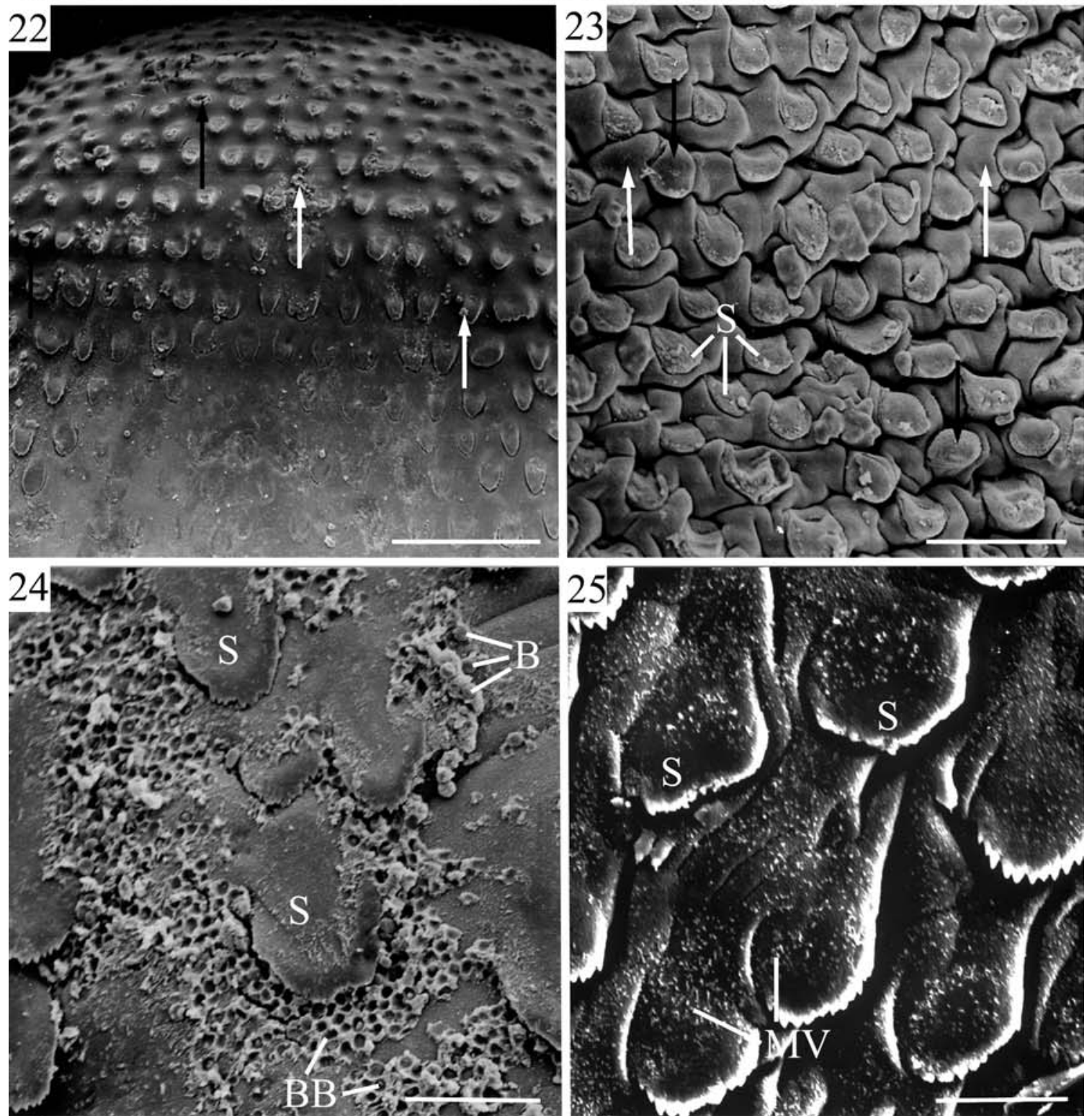
Figs. 26-29 Scanning electron micrographs (SEMs) of the gut of red blood cell-fed control (Figs. 26, 27) and clorsulon-bound red blood cell-fed (Figs. 28, 29) Fasciola hepatica which had been incubated in vitro for $24 \mathrm{~h}$

Fig. 26 High-power SEM of a region of gut from a control fluke showing the rippled lamellae $(L)$ extending into the gut lumen. Bar $150 \mu \mathrm{m}$

Fig. 27 High-power SEM showing rippled lamellae $(L)$ extending into the lumen of a section of control gut. The surface of the lamellae is roughened with microvillus-like projections (arrows). Bar $50 \mu \mathrm{m}$

Fig. 28 Gut lumen showing severely disrupted lamellae $(L)$ which have almost totally lost their normal appearance and organisation. Bar $200 \mu \mathrm{m}$

Fig. 29 Disrupted gut lamellae $(L)$ which have lost their normal structure and look very frayed. Bar $100 \mu \mathrm{m}$ 


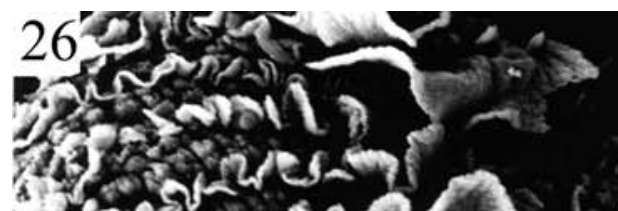

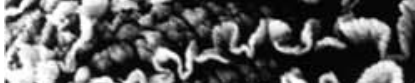

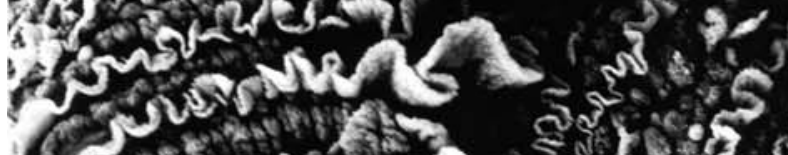

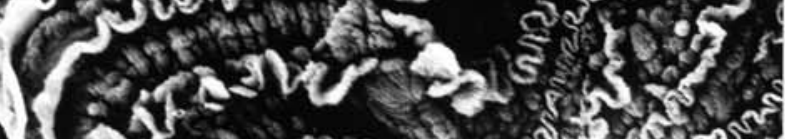

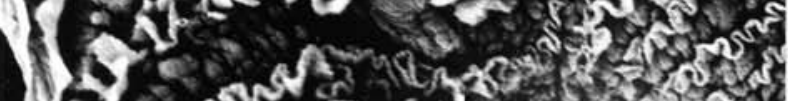

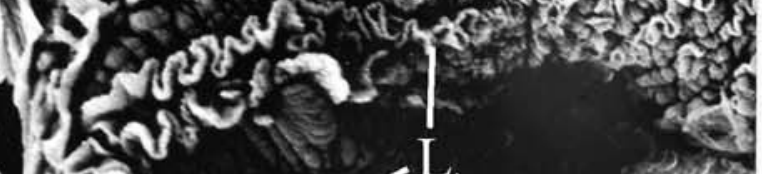

A.

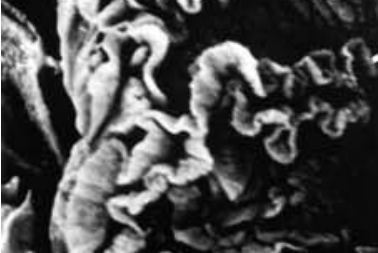

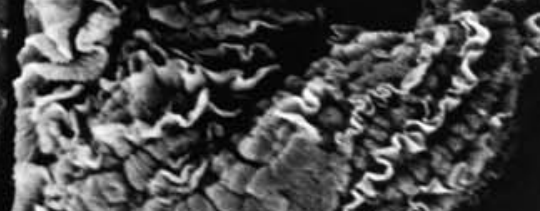

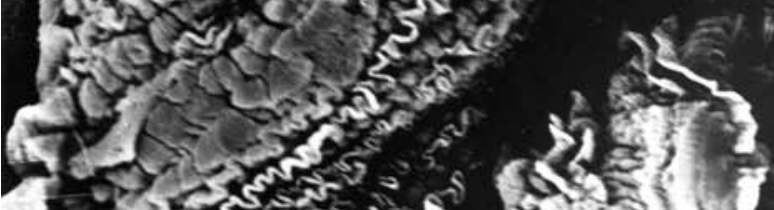

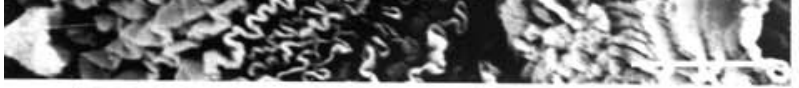

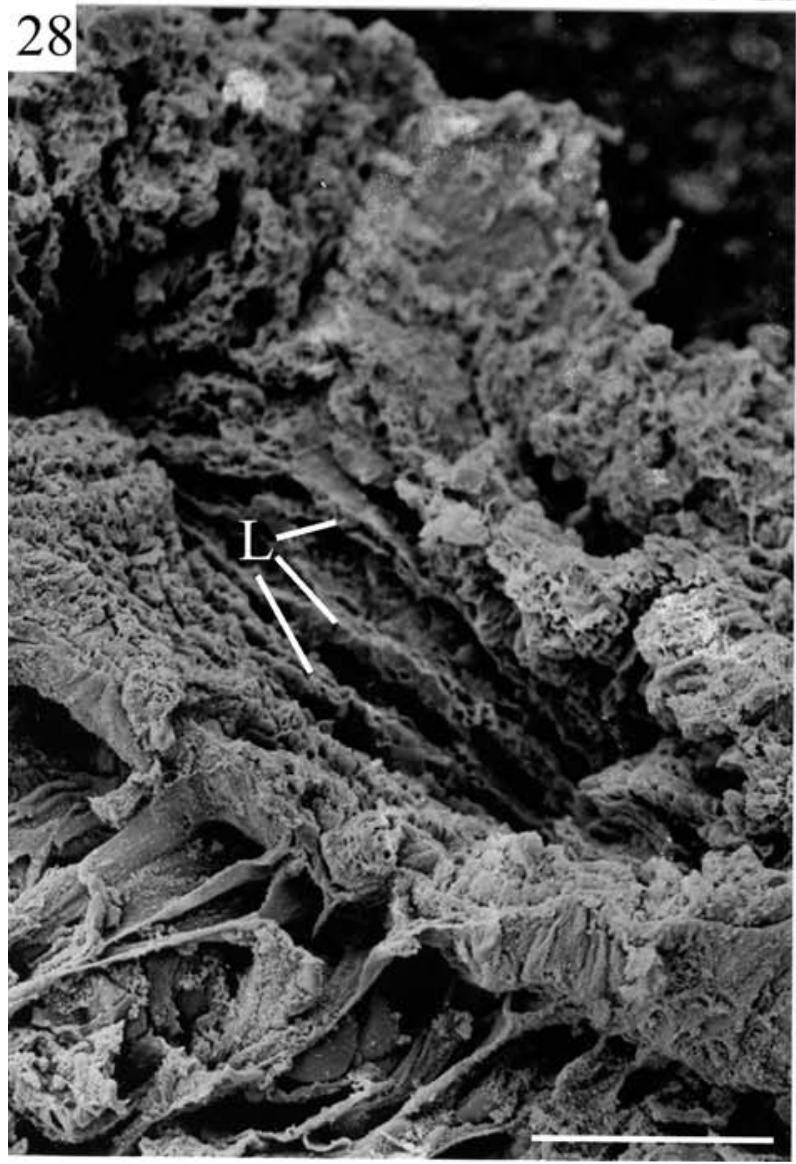

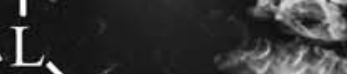

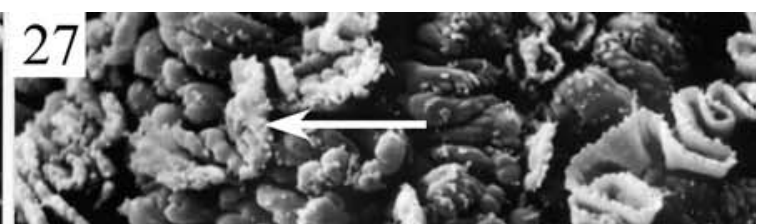

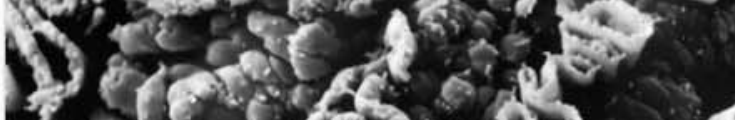

(2)
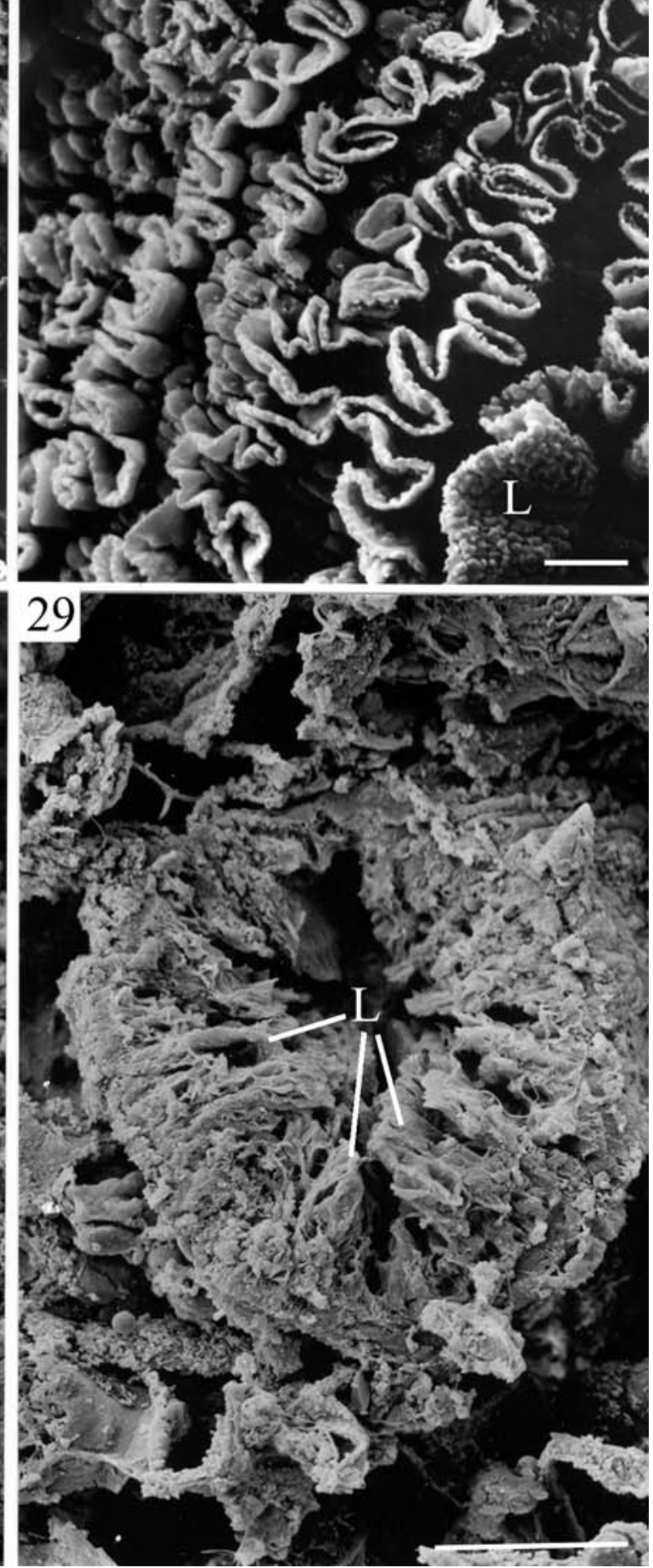